\title{
Thermal Vacuum Testing of a Novel Loop Heat Pipe Design for the Swift BAT Instrument
}

\author{
Laura Ottenstein ${ }^{1}$, Jentung $\mathrm{Ku}^{1}$, David Feenan ${ }^{2}$ \\ 'Thermal Engineering Branch, NASA/Goddard Space Flight Center, Code 545, Greenbelt, MD 20771 \\ ${ }^{2}$ Swales Aerospace, 5050 Power Mill Road, Beltsville, Maryland, 20705 \\ (301)286-4141; laura.ottenstein@gsfc.nasa.gov
}

\begin{abstract}
An advanced thermal control system for the Burst Alert Telescope on the Swift satellite has been designed and an engineering test unit (ETU) has been built and tested in a thermal vacuum chamber. The ETU assembly consists of a propylene loop heat pipe, two constant conductance heat pipes, a variable conductance heat pipe (VCHP), which is used for rough temperature control of the system, and a radiator. The entire assembly was tested in a thermal vacuum chamber at NASA/GSFC in early 2002. Tests were performed with thermal mass to represent the instrument and with electrical resistance heaters providing the heat to be transferred. Start-up and heat transfer of over $300 \mathrm{~W}$ was demonstrated with both steady and variable condenser sink temperatures. Radiator sink temperatures ranged from a high of approximately $273 \mathrm{~K}$, to a low of approximately $83 \mathrm{~K}$, and the system was held at a constant operating temperature of $278 \mathrm{~K}$ throughout most of the testing. A novel LHP temperature control methodology using both temperature-controlled electrical resistance heaters and a small VCHP was demonstrated. This paper describes the system and the tests performed and includes a discussion of the test results.
\end{abstract}

\section{INTRODUCTION}

Loop heat pipes (LHP's) are robust, self-starting, and passive two-phase thermal transport devices (Ku, 1999). They utilize the latent heat of vaporization of a working fluid to transfer heat, and the surface tension forces formed in a fine-pore capillary wick to circulate the working fluid. They are used to transport excess heat from a heat source such as a payload instrument in a spacecraft to a lower temperature heat sink, while maintaining the instrument temperature within specified limits. They have found increasing acceptance in satellites where there is a significant amount of energy to be transferred and a need to thermally uncouple the instrument from the radiator in some operating conditions to conserve heater power. Loop heat pipes are used or planned for a number of upcoming missions, including Aura, GOES, ICESAT, a number of communication satellites, and the Burst Alert Telescope on Swift.

\section{Background}

The Swift satellite is a multi-wavelength observatory that will be launched on a Delta rocket in late 2003. Swift contains three instruments - a wide-field gamma ray burst detector and two sensitive narrow-field telescopes to identify and follow the X-ray, UV, and optical afterglow. The Burst Alert Telescope (BAT) is a large coded aperture instrument with a wide field-of-view and will observe and locate hundreds of bursts per year to better than 4 arc minutes accuracy. Using this prompt burst location information, Swift can slew quickly to point the telescopes at the burst for continued afterglow studies.

The BAT instrument consists of a large hard $\mathrm{x}$-ray detector plane positioned one meter away from an even larger coded aperture mask, as shown in Figure 1. The BAT detector plane holds $256 \mathrm{CdZnTe}$ semiconductor detector modules, each containing 128 individual detectors. In each module the signals from these 128 detectors are read out 
by a single XA1 Application Specific Integrated Circuit. The detector array plate (DAP) contains eight embedded constant conductance heat pipes that transfer the heat from the detectors and associated electronics to the edges of the DAP. Two loop heat pipe evaporators are mounted to the edges of the DAP. The LHP's transfer the heat to a single shared radiator on the side of the instrument, where it is ultimately rejected to space.

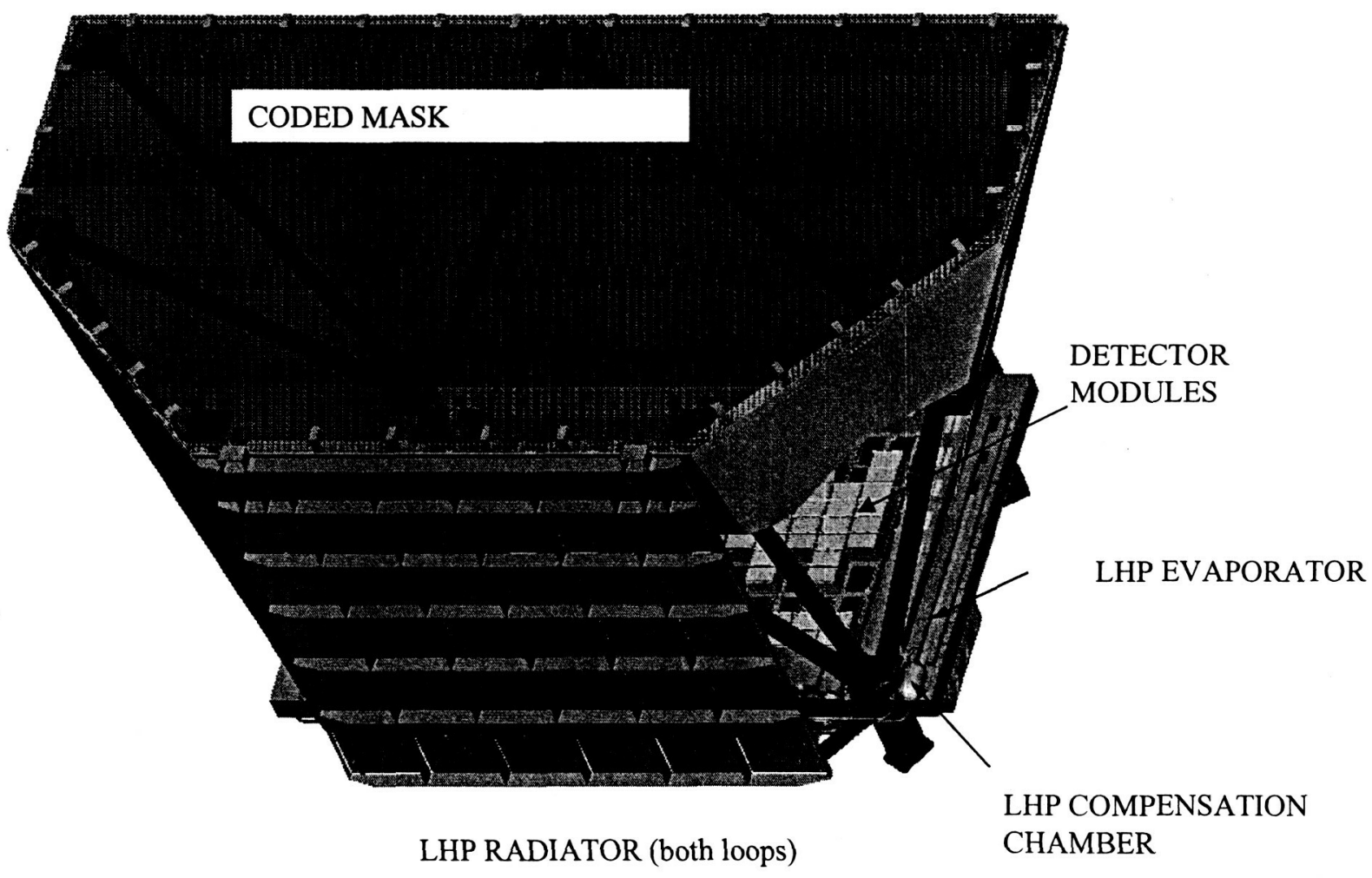

FIGURE 1. Burst Alert Telescope.

\section{Requirements}

There were a number of thermal requirements for the BAT instrument that influenced the design for the thermal control system. The gamma ray detectors must be held within a gradient of $\pm 0.5 \mathrm{~K}$ across the entire detector array of $1.6 \times 0.94$ meters and over any time period. Heat to be transported is relatively constant, with $221 \mathrm{~W}$ dissipated by the detector modules and their control electronics, and variable controlled heater power of up to $32 \mathrm{~W}$ that is used to provide fine control of local temperature gradients. This means that with $50 \%$ margin, the system needs to be capable of transporting $380 \mathrm{~W}$. Although the nominal operating condition is for both loops to run concurrently, the system was designed so that one LHP can transfer the entire load, including the $50 \%$ margin. Power available to the thermal control system (per loop heat pipe) consists of $20 \mathrm{~W}$ of control heater power, $60 \mathrm{~W}$ of starter heater power, which is available only before all of the block modules are activated, and $15 \mathrm{~W}$ during survival mode which is used to shut down the LHP. 


\section{ENGINEERING TEST UNIT DESCRIPTION}

In order to verify the design for the BAT loop heat pipes, an engineering test unit (ETU) was built and tested in a thermal vacuum chamber at Goddard Space Flight Center. Although the flight system will consist of two LHP's, a single unit, as shown in Figure 2, was built for testing due to funding limitations. The ETU assembly consists of a single propylene loop heat pipe, two constant conductance heat pipes (CCHPs), a variable conductance heat pipe, and a radiator plate. The loop heat pipe has a single evaporator and compensation chamber (CC), and two parallel condensers with associated flow regulators. The CCHPs are bonded to the sides of the evaporator and are used to transfer heat from the portion of the DAP that is not under the LHP evaporator to the evaporator.

The operating temperature of a loop heat pipe is governed by the $\mathrm{CC}$ temperature. In most designs, the $\mathrm{CC}$ is cold biased and heater power is provided to maintain the set point temperature. Under certain conditions, the heater power requirements can be substantial. In order to lower the heater power consumption, some LHPs use crossstrapping of the vapor and liquid lines (Baker, 2001, Bienert, 1999). However, such a design can contribute to startup difficulties and was not sufficient in this case. In this system, a VCHP provides rough temperature control of the LHP by pre-conditioning the liquid returning to the CC. The VCHP evaporator is bonded to the LHP evaporator with an aluminum saddle. The VCHP condenser is part of an integral heat exchanger in the LHP liquid return line. The VCHP reservoir temperature is controlled using a feedback sensor located on the outlet of the liquid line heat exchanger. A temperature controller was provided by the BAT instrument that controlled both the CC heaters and the VCHP heater. The set point temperature for the VCHP was defined as an offset, originally $8 \mathrm{~K}$, from the CC set point. When the liquid return line temperature was above the set point, the VCHP heater was turned ON to shut down the VCHP. When the return line temperature was below the set point, the VCHP heater was turned OFF to allow the VCHP to operate.

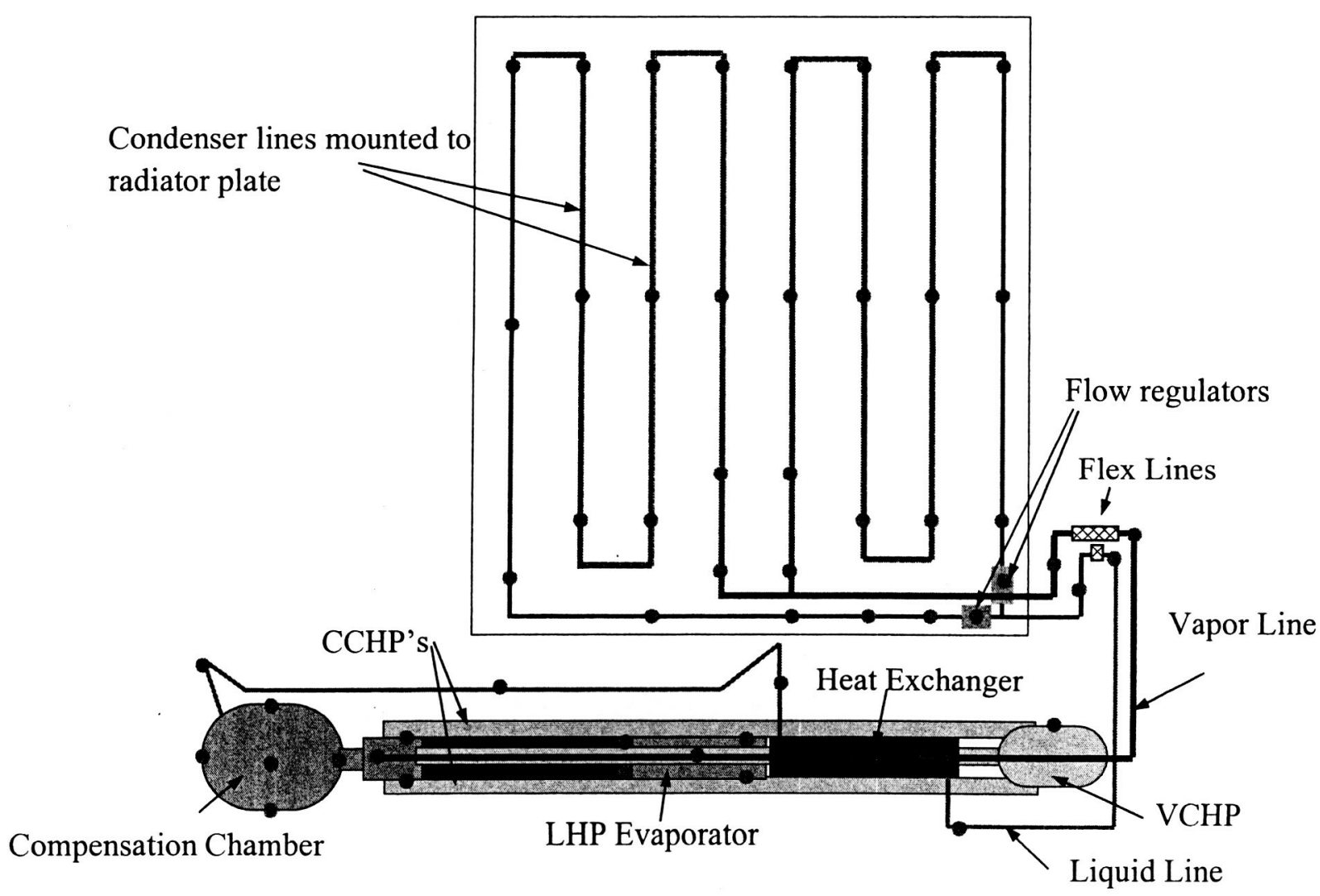

FIGURE 2. Loop Heat Pipe Schematic. 


\section{TEST SET-UP}

The ETU LHP was tested in a thermal vacuum chamber at GSFC in two different configurations - a reflux configuration, and a horizontal configuration. In both configurations, the data was collected using a NEFF data acquisition system, and displayed on a PC using LabView software. Evaporator starter heaters and thermal mass heaters were controlled manually by the test operator. Two cooling plates, one over the radiator and one over the evaporator assembly, were used to control the local environment. The cooling plates had both liquid nitrogen cooling lines and heaters attached, and were individually computer controlled to follow predetermined thermal profiles that simulate the on-orbit environment. The vacuum chamber itself did not have a shroud, and the chamber walls were not cold during the test. Flight-like MLI was installed on the transport lines, the back of the radiator, the VCHP, and the evaporator/CC assembly. MLI was also installed on the back of the cooling plates.

\section{Reflux}

The reflux configuration, shown in Figure 3, was designed to test the loop in a configuration similar to what will be seen in the instrument and spacecraft thermal vacuum testing. Since the chamber was too small for the radiator to be purely vertical, the radiator was held at an angle of approximately $60^{\circ}$. As this still yields a significant gravity effect on the condenser, this should adequately reflect the performance in the spacecraft configuration. In this case, the LHP evaporator was mounted to the flight DAP. Since there was no electronics mounted to this plate, test masses with electrical heaters were mounted to the top and bottom of the plate to simulate the instrument electronics. The total mass attached to the LHP evaporator, including the tests masses and the DAP, was approximately $127 \mathrm{~kg}$. For handling purposes, the total mass required was divided into eight sections for the top of the plate and four sections for the bottom of the plate.

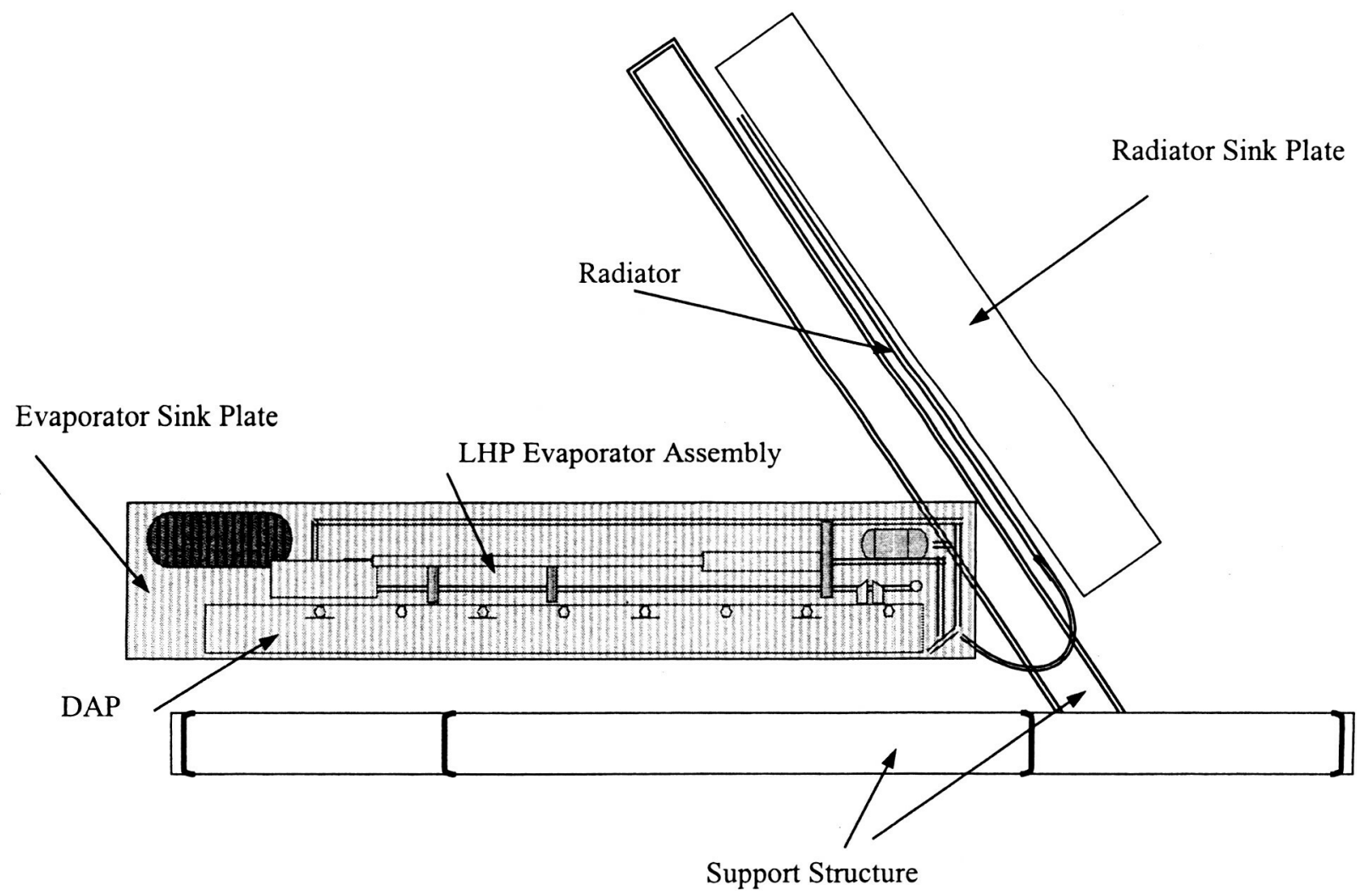

FIGURE 3. Reflux Test Configuration. 


\section{Horizontal}

The horizontal configuration was tested after the reflux configuration. The purpose of the horizontal test was to verify that the loop operated as designed, without assistance from gravity. Since the DAP was required for other spacecraft activities, the LHP evaporator was removed from the DAP and mounted on four test heat pipes which in turn were mounted to four test thermal masses $(27 \mathrm{~kg}$ each) to simulate the DAP and attached electronics. Each thermal mass contained two cartridge heaters to simulate the instrument power to be dissipated. The radiator was held horizontal next to the evaporator assembly. Due to the limitations of the flex lines, the radiator was slightly below the level of the evaporator assembly. The sink plate was located below the radiator plate, and the evaporator cold shroud was again used.

\section{TEST PLAN}

The test plan was designed to verify all aspects of the flight operation. Three basic environments were tested worst case hot, worst case cold, and a worst case transition that combined the coldest portion of the cold orbit with the warmest portion of the hot orbit. The basic operation to be verified consisted of $50 \%$, full power, and $150 \%$ power operation at cold and hot operating extremes. Start-ups of the loop in both hot and cold conditions were performed. The primary purpose of these tests was to verify the adequacy of the thermal control system, including the controller, the VCHP operation, and the amount of heater power on the CC and VCHP reservoir. Shut down tests were done to verify that the system would shut down as required during the transition to survival mode and stay shut down under survival conditions. The majority of the tests were done with orbit profiles imposed on the cold sink plates. Sink profiles for the nominal power case are shown in Figure 4.

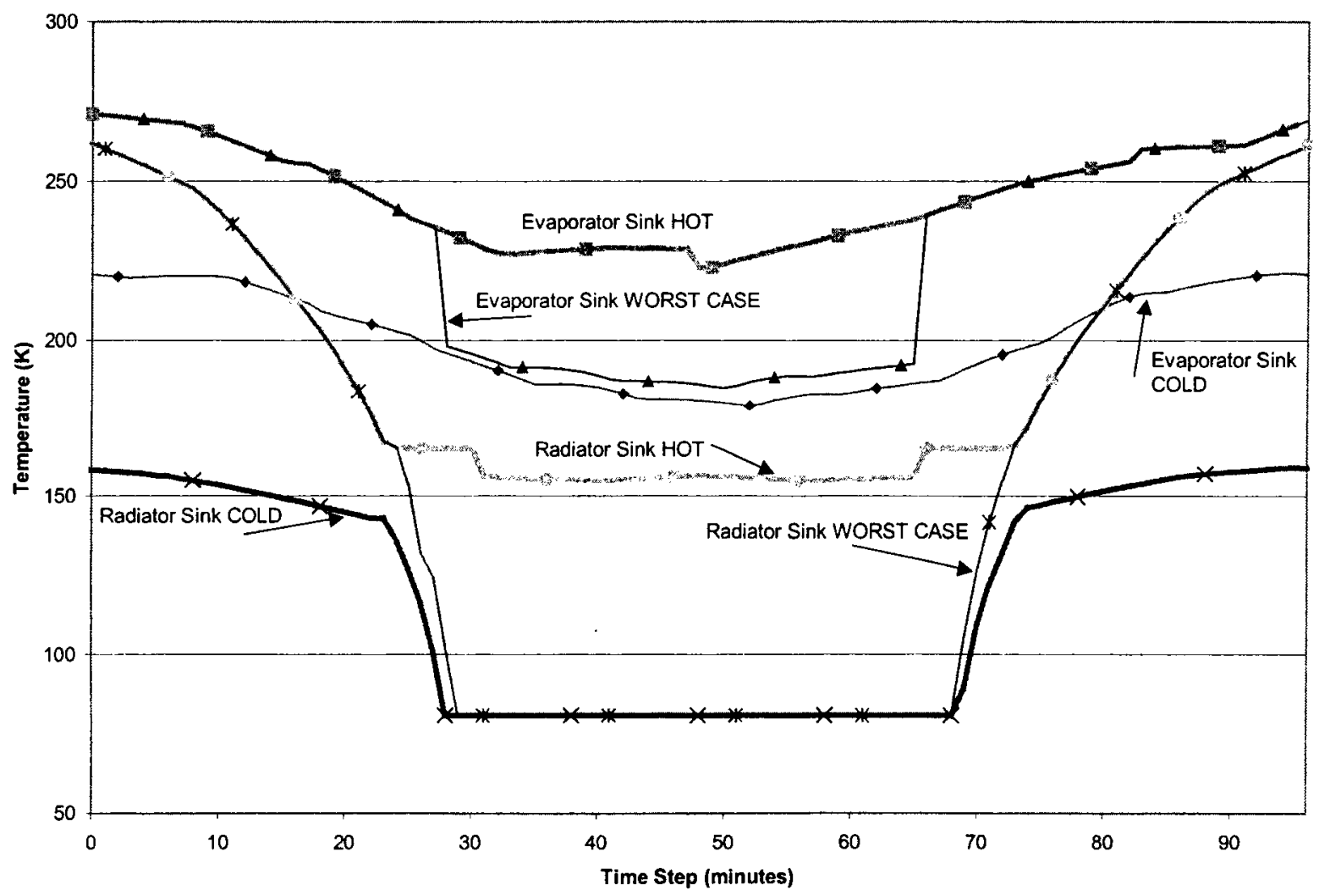

FIGURE 4. Sink Temperature Profiles for $100 \%$ Power Condition. 


\section{TEST RESULTS}

\section{Start-Ups}

Before the loop was started, the thermal mass was allowed to cool below $278 \mathrm{~K}$ and the $\mathrm{CC}$ heater was turned on with a $278 \mathrm{~K}$ set point. After the CC had reached the desired set point, $60 \mathrm{~W}$ was applied to the LHP evaporator using the starter heater. Start-ups were performed by applying $60 \mathrm{~W}$ with the starter heater, and with a varying amount of power on the thermal masses. In the initial start-up procedure, the loop was started using just the starter heater power (no thermal mass power). Once the loop had started, thermal mass power was applied and then increased in steps. The starter heater power was removed when the thermal mass power reached $180 \mathrm{~W}$. However, at this point, most of the power applied was being used to heat up the thermal mass and very little of it was going into the loop heat pipe. The resultant low fluid flow meant that the return liquid was not cold enough to maintain the saturation temperature in the $\mathrm{CC}$ and positive control of the loop saturation temperature was lost, as shown in Figure 5. When the starter heater was turned back on, the loop recovered. The starter heater was then left on until the thermal mass temperatures were relatively stable and above the evaporator temperature. At this point, the starter heater was turned off and the thermal mass power was increased in steps to $100 \%$ power. In subsequent start-ups, power was applied to the thermal masses when the starter heater was turned on. The loop performed well for all of these test cases.

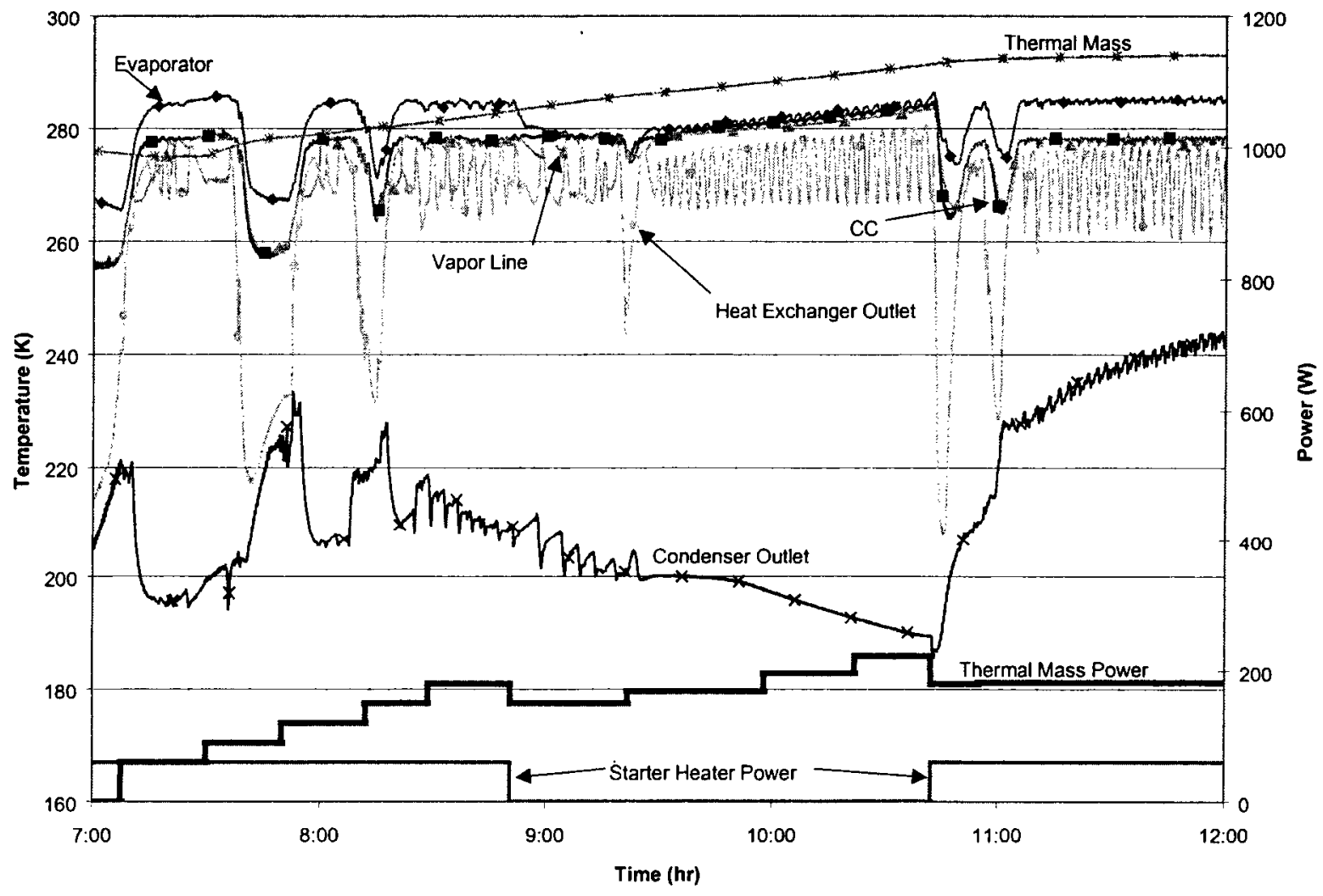

FIGURE 5. Start-Up with Temporary Loss of Saturation Temperature Control, 1/17/2002. 
Often, when the loop started, there was a sudden influx of cold liquid into the $\mathrm{CC}$ from the condenser, resulting in a rapid temperature decrease (cold shock). In this case, the VCHP response was much too slow to prevent a rapid decrease in saturation temperature. However, the instrument is not operational during the start-up process, and the cold shock does not bring the electronics below their cold temperature limit, so it was not considered a problem. The cold shock was smaller during the horizontal start-ups, which should be more reflective of the flight operation of the system.

The evaporator/CC was surrounded by a cold shroud to mimic the view to space seen on the spacecraft. The CC was partially coated with silver Teflon tape to cold bias it and guarantee that positive temperature control could be maintained at all times. As a result, when the shroud was cooled, the CC cooled faster than the evaporator. This temperature difference usually resulted in a self start of the LHP. This was seen repeatedly during the testing. As the $\mathrm{CC}$ and radiator were cooled, the fluid would begin circulating. This in turn would inject cold liquid into the $\mathrm{CC}$, further lowering its temperature. Cold shocks were also seen periodically during the cold environment testing in the reflux configuration.

\section{Temperature Control}

The primary method of maintaining control of the LHP saturation temperature was through two heaters $(5 \mathrm{~W}$ each at $28 \mathrm{~V}$ ) on the CC. These heaters were controlled by two separate feedback circuits in the temperature controller. The feedback thermistors were mounted on the top of the CC. The set point was the same for each heater and was generally $278 \mathrm{~K}$ during the test. Since $10 \mathrm{~W}$ was not sufficient to maintain the setpoint during cold environmental conditions, the VCHP was used to provide rough conditioning of the liquid returning to the CC. The control thermistor for the VCHP was on the liquid line where it exits the heat exchanger. When this temperature was colder than the desired set point, the VCHP heater was off and the VCHP transferred heat from the evaporator directly to the returning liquid. When the feed back temperature was above the set point, the gas reservoir heater was turned on to shut down the VCHP and stop the heat transfer to this line. Overall, the control scheme worked as designed, although the response time was slow enough that the $\mathrm{CC}$ was not always maintained at the desired set point. There was a particularly slow response when the VCHP reservoir heater had been on for a significant period of time (because a warm environment was resulting in very little subcooling) and was then shut off. The VCHP would not begin operating until the gas reservoir had cooled to near the heat pipe adiabatic section temperature, sometimes taking up to one hour. Although this did cause the CC temperature to drop below the set point, there was very little effect on the thermal mass temperatures. The control scheme introduced temperature oscillations throughout the LHP system, but since these also did not have a significant effect on the thermal masses, they were not considered a problem.

\section{Transition to Fixed Conductance}

At some higher power levels, the sink conditions at the warm end of the environmental temperature profile were not sufficient to allow all of the heat to be rejected. When this occurred, the loop automatically transitioned to fix conductance mode. This happened because the condenser opened far enough to completely fill the CC with liquid. At this point, the $\mathrm{CC}$ no longer controlled the saturation temperature, and the saturation temperature rose to permit the required heat rejection, as shown in Figure 6. After removing some conservative assumptions from the power and sink temperature calculations, the system was able to reject all of the heat in the $100 \%$ power hot case without transitioning to fixed conductance. Even when the system did transition to fixed conductance, the total change in the thermal mass temperature was only $\pm 0.1 \mathrm{~K}$. 


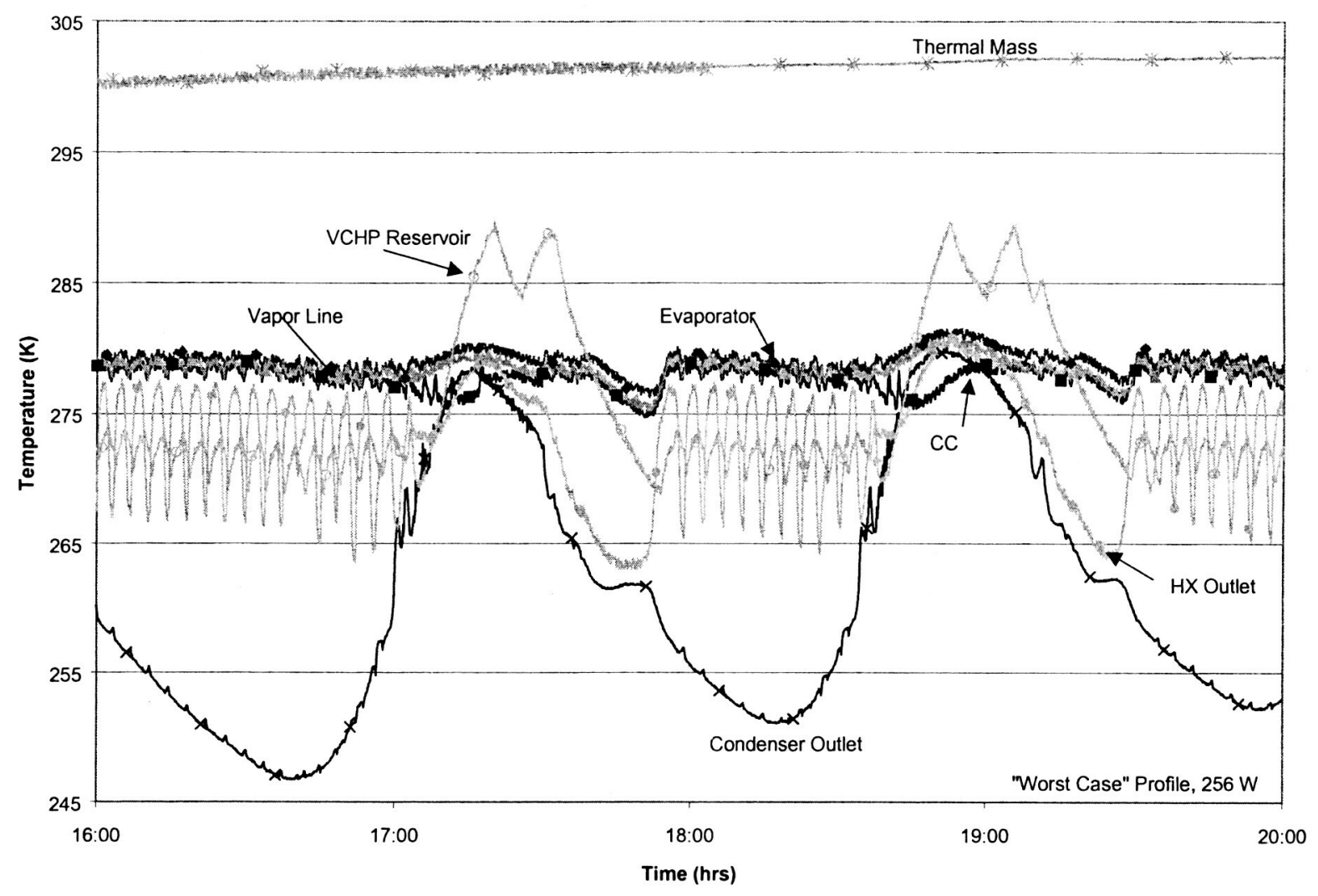

FIGURE 6. Transitions to Fixed Conductance, 2/21/02.

\section{Shutdown Testing}

The loop is required to shutdown when the satellite enters safe-hold conditions in order to thermally de-couple the instrument from the radiator and lower the survival heater power requirements. Fifteen watts of survival heater power is available during the survival mode to shutdown the loop and keep it shutdown. Several shutdown tests were performed during this testing. The temperature profile from one test is shown in Figure 7 . In the test, power was removed from the thermal masses, CC, and VCHP reservoir, while the sink plates continued to follow the cold profile. The loop temperatures dropped slowly as the CC cooled down until the survival heater thermostat on the $\mathrm{CC}$ activated the survival heater. At this point, the $\mathrm{CC}$ temperature rose until the survival heater thermostat opened again. In each test, this first cycle of the survival heater did not shut down the loop because there was still significant heat into the loop from the warm thermal masses. As the mass temperatures continued to drop, the loop would shutdown and then restart. The restart would result in a cold shock of the $\mathrm{CC}$, which would rapidly drop both the $\mathrm{CC}$ temperature and the mass temperature. When the thermal masses had cooled to a temperature near the CC temperature, the CC survival heater shut the system down permanently, demonstrating proper loop shutdown. 


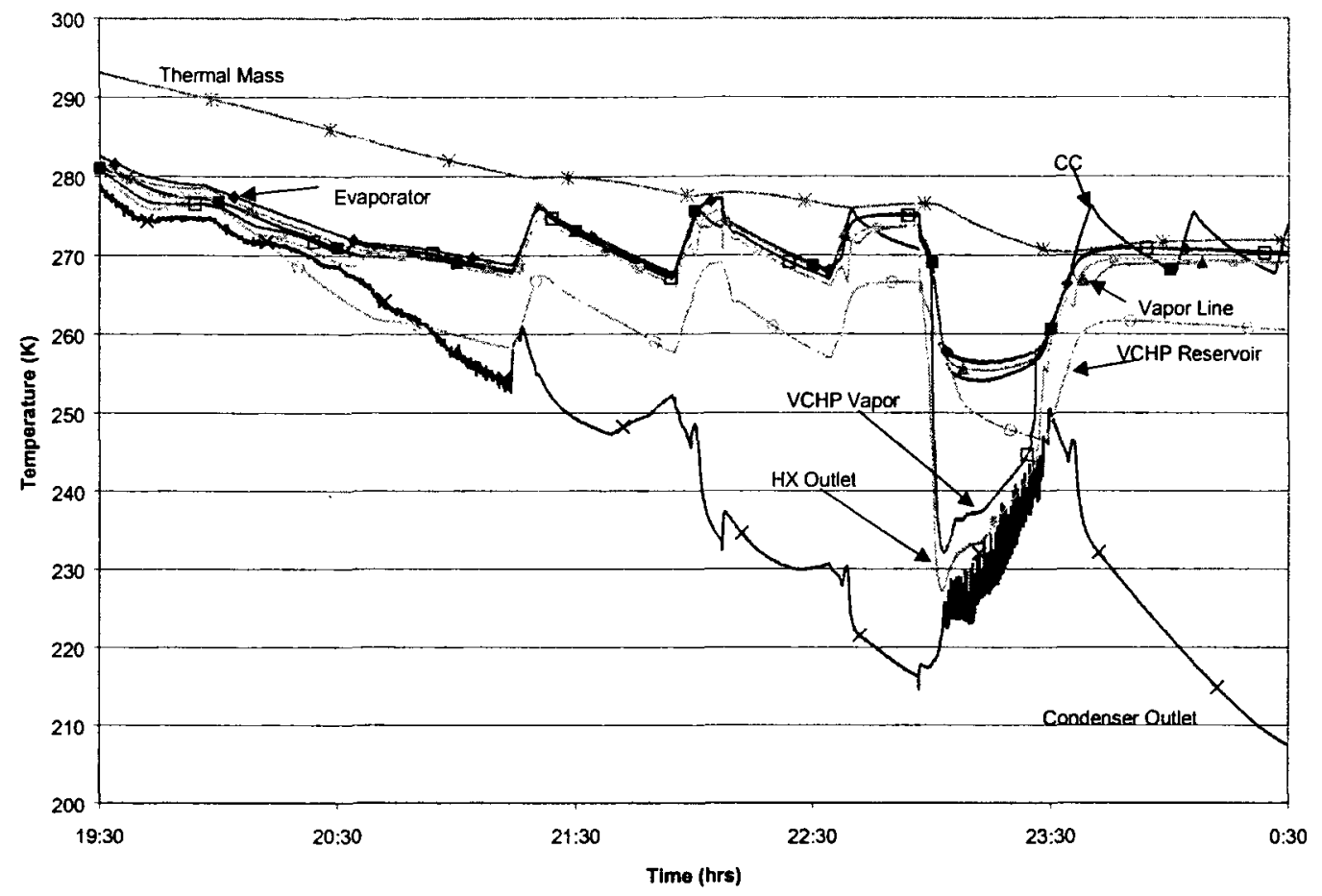

FIGURE 7. Shutdown Test, $1 / 22-23 / 2002$.

\section{CONCLUSIONS}

The thermal vacuum testing verified that the BAT thermal system design is acceptable. Based on the test results, the start-up procedure was modified to assure long term stable operation. The control scheme, with the VCHP, was generally able to maintain the $\mathrm{CC}$ within the desired temperature range. Even when the $\mathrm{CC}$ temperature was not within the desired range, the temperature variation at the thermal masses was still within specifications. Although power above nominal often resulted in fixed conductance operation, nominal power operation was acceptable in all environmental conditions. In addition, even in fixed conductance operation, the temperature requirements of the instrument were met. The shut down operation was also demonstrated successfully.

\section{ACKNOWLEDGMENTS}

The BAT loop heat pipes system was designed and built by Swales Aerospace.

\section{REFERENCES}

Baker, C., Butler, D., Ku, J., and Grob, E., "Acceptance Thermal Vacuum Tests of the GLAS Flight Loop Heat Pipe Systems," Space Technology and Applications International Forum, Albuquerque, New Mexico, 2001.

Bienert, W., Krotiuk, W., and Nikitkin, M., "Thermal Control with Low Power, Miniature Loop Heat Pipes," Paper No. 1999-01 2008, presented at $29^{\text {th }}$ International Conference on Environmental Systems, Denver, Colorado, July 12-15, 1999.

$\mathrm{Ku}$, J., "Operating Characteristics of Loop Heat Pipes," Paper No. 1999-01-2007, presented at $29^{\text {th }}$ International Conference on Environmental Systems, Denver, Colorado, July 12-15, 1999. 